\title{
Estudo Experimental das Propriedades da Palha de Cana-de-açúcar e sua Cinética de Decomposição em Meio Oxidante
}

\author{
Luísa A. Higuchi (IC), Yesid J. Rueda-Ordóñez (PG), Katia Tannous (PQ)
}

\section{Resumo}

O objetivo deste trabalho é estudar a cinética da decomposição térmica da palha da cana-de-açúcar (253$1021 \mu \mathrm{m})$ em meio oxidante, mediante análise termogravimétrica $\left(2,5-10^{\circ} \mathrm{C} / \mathrm{min}\right)$ com aplicação do modelo das reações paralelas e independentes. Seis reações foram assumidas representando os processos de liberação de voláteis e de combustão para os principais componentes (celulose, hemicelulose e lignina), e energias de ativação entre $142-316 \mathrm{~kJ} / \mathrm{mol}$ e $93-132 \mathrm{~kJ} / \mathrm{mol}$, respectivamente.

Palavras Chave: Bioenergia, Termodecomposição, Resíduos.

\section{Introdução}

A termoconversão de biomassas vegetais pode se dar por meio dos processos de combustão, gaseificação ou pirólise. Esta última é largamente estudada em atmosfera inerte, porém em grande escala ocorre na presença de oxigênio. Por isso, o objetivo deste trabalho foi estudar a cinética de decomposição da palha da cana-de-açúcar, em atmosfera oxidante, através da análise termogravimétrica.

\section{Resultados e Discussão}

A palha de cana-de-açúcar utilizada neste trabalho apresentou as seguintes características: diâmetro de partícula $(\mu \mathrm{m})$ : 253,510 e 1021; massa específica aparente e real $\left(\mathrm{g} / \mathrm{cm}^{3}\right): 0,60$ e 1,82-2,18; esfericidade (-): $0,31-0,47$; umidade (\%b.u.): 8,4 ; composição química (\%b.s.): hemicelulose $(34,7)$, celulose $(34,6)$, lignina $(21,6)$; composição elementar (\%b.s.): Carbono (43), Hidrogênio $(6,3)$, Nitrogênio $(0,3)$, Oxigênio (46); análise imediata (\%b.s): materiais voláteis $(86,6)$, cinzas $(3,8)$, carbono fixo $(9,5)$; $\mathrm{PCS} / \mathrm{PCl}$ $(\mathrm{MJ} / \mathrm{kg}): 18,61 / 15,72$. A análise termogravimétrica (TGA) foi realizada em atmosfera de ar sintético $\left(80 \% \quad \mathrm{~N}_{2}, 20 \% \mathrm{O}_{2}\right)$ e a partir dos dados de evolução da massa decomposta em função da temperatura (TG e DTG), calculou-se a conversão $\left(\alpha_{\text {exp }}\right)$ e a taxa de conversão $(d \alpha / d t)_{\text {exp. }}$. Após, foram determinadas as $(d \alpha / d t)_{\text {teo }}$, segundo a lei de Arrhenius assumindo seis reações (frações pirolisáveis e não-pirolisáveis de hemicelulose, celulose e lignina) e aplicação do modelo de reações paralelas e independentes (RPI) (Órfão, 1999). Aplicou-se tratamento estatístico pelos mínimos quadrados. Os parâmetros cinéticos, fator pré-exponencial $(A)$ e energia de ativação (E) foram determinados seguindo reação de primeira ordem (Tabela 1). Um exemplo $\left(d_{p}=510 \mu \mathrm{m}\right.$ e $\left.\beta=10^{\circ} \mathrm{C} / \mathrm{min}\right)$ das curvas de taxas de conversão referentes a cada reação está mostrado na Figura 2. As energias de ativação obtidas foram entre $142-316 \mathrm{~kJ} / \mathrm{mol}$ e $93-132$ $\mathrm{kJ} / \mathrm{mol}$, respectivamente.

Tabela 1. Modelo RPI e tratamento estatístico $\begin{array}{lc}\alpha_{\text {exp }}=\left(m_{i}-m_{t}\right) /\left(m_{i}-m_{f}\right) & \text { Tratamento Estatístico } \\ (d \alpha / d t)_{\text {exp }}=\left(-d m_{i} / d t\right)\left[1 /\left(m_{i}-m_{f}\right)\right] & S S=\sum_{i=0}^{N}\left((d \alpha / d t)_{\text {exp }, i}-(d \alpha / d t)_{t e o, i}\right)^{2} \\ (d \alpha / d t)_{\text {teo,i }}=A\left(1-\alpha_{\text {teo }}\right)^{n} \exp [-E /(R T)] & \sqrt{\frac{S S}{N}} \\ (d \alpha / d t)_{\text {teórico }}=\sum_{i}^{N} F_{i}(d \alpha / d t)_{i} & \mathrm{DR}(\%)=\frac{\sqrt{d a}}{\left(\frac{d a}{d t}\right)_{\text {exp, max }}} 100 \\ \mathrm{~N}=4,5,6 & \end{array}$

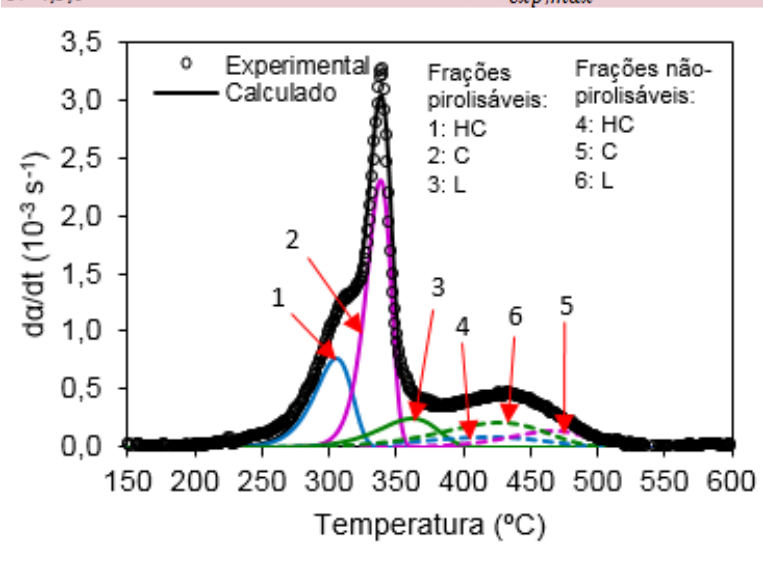

Figura 2. Taxa de conversão para o modelo RPI

\section{Conclusões}

O modelo das RPI com 6 reações representou satisfatoriamente a cinética de decomposição da palha de cana-de-açúcar em atmosfera oxidante através do modelo de reações paralelas e independentes com desvios relativos $(D R \%)$ de no máximo $2,90 \%$.

\section{Agradecimentos}

Os autores agradecem aos colegas de laboratório e o apoio financeiro do CNPq.

Órfão, J. J. M.; Antunes, F. J. A. e Figueiredo, J. L. Fuel, 1999, 78 (3), p.349-358 